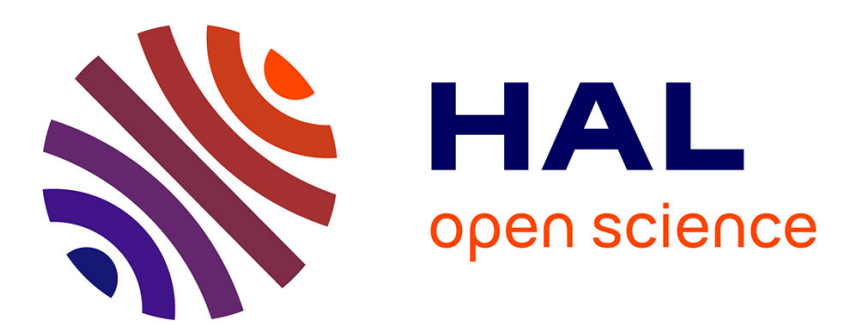

\title{
A better understanding of functional roles of fungi in the decomposition process: using precursor rRNA containing ITS regions as a marker for the active fungal community
}

Purahong, Krüger

\section{To cite this version:}

Purahong, Krüger. A better understanding of functional roles of fungi in the decomposition process: using precursor rRNA containing ITS regions as a marker for the active fungal community. Annals of Forest Science, 2012, 69 (6), pp.659-662. 10.1007/s13595-012-0210-7 . hal-00930859

\section{HAL Id: hal-00930859 \\ https://hal.science/hal-00930859}

Submitted on 1 Jan 2012

HAL is a multi-disciplinary open access archive for the deposit and dissemination of scientific research documents, whether they are published or not. The documents may come from teaching and research institutions in France or abroad, or from public or private research centers.
L'archive ouverte pluridisciplinaire HAL, est destinée au dépôt et à la diffusion de documents scientifiques de niveau recherche, publiés ou non, émanant des établissements d'enseignement et de recherche français ou étrangers, des laboratoires publics ou privés. 


\title{
A better understanding of functional roles of fungi in the decomposition process: using precursor rRNA containing ITS regions as a marker for the active fungal community
}

\author{
Witoon Purahong • Dirk Krüger
}

Received: 2 January 2012 / Accepted: 9 April 2012 /Published online: 8 May 2012

(C) INRA / Springer-Verlag France 2012

\section{Introduction}

Decomposition and biogeochemical cycling are important ecosystem services provided by fungi (Kulhánková et al. 2006; Gange et al. 2007; Trap et al. 2011). Hitherto, different approaches have been used to examine the fungal community and its functional role in the decomposition process. Culture-dependent approaches have limitations because most fungi in environmental samples are likely to be uncultivable or difficult to isolate and such approaches are biased towards fast-growing fungi and affected by media selection (Anderson and Cairney 2004). On the other hand, cultureindependent molecular approaches are used routinely for fungal diversity and community assessment. The main targets of these approaches are the rRNA genes and spacer regions of the RNA operon (rDNA), thus basing diversity and community composition on DNA content. However, some studies show that DNA may have a long life span in the environment (Nielsen et al. 2004; Levy-Booth et al. 2007; Corinaldesi et al. 2008; Pietramellara et al. 2009).

\section{Handling Editor: Ana Rincon}

Contribution of the co-authors Witoon Purahong: writing the paper Dirk Krüger: writing the paper and supervising the work

W. Purahong $(\bowtie) \cdot$ D. Krüger

Department of Soil Ecology, UFZ - Helmholtz Centre

for Environmental Research,

Theodor-Lieser-Strasse 4

06120 Halle (Saale), Germany

e-mail: witoon.purahong@ufz.de

W. Purahong

Chair for Soil Ecology, Technical University of Munich,

Ingolstädter Landstrasse 1,

85758 Oberschleissheim, Germany
DNA can stem from fungal resting structures and spores or even senescent mycelium, all of which would be metabolically inactive at a given sampling time and even permanently. Consequently, fungal community details from DNA carry some memories about the previous community composition, and may poorly reflect the fungi that are active in decomposition processes at the time of sample collection. Additionally, it is possible that dispersed propagules leave their DNA signatures when they are carried there by wind or animals (Stenlid and Gustafsson 2001). The operational taxonomic unit (OTU) richness of decomposer fungal communities revealed by DNA-based community assessment is usually higher than that based on RNA because of the inclusion of dead or inactive fungal DNA (Anderson and Parkin 2007; Rajala et al. 2011). However, there were few cases reported vice versa or no significant differences between OTU richness of the fungal decomposers derived either by DNA- or RNA-based approaches (Bastias et al. 2007; Baldrian et al. 2012). These are because some fungal OTUs are only detected using RNA and they compensate the inactive fungi detected by DNA. Nevertheless, we suggest caution that the presence of background communities of dormant or senescent fungi in environmental samples as an artifact is a potentially major hindrance to unbiased interpretation of real functional roles and correlations with enzyme production and environmental parameters. A DNAbased study (Kulhánková et al. 2006; Kubartová et al. 2009) has revealed that a large proportion of ascomycetes produce few oxidative enzymes and so are restricted in their ability to digest complex substances in the late stages of decomposition. Inactive or dead Ascomycota may be remnants of earlier stages of decomposition (Purahong and Hyde 2011; Rajala et al. 2011), which strongly supports the suggestion that there is an inert background fungal community, and that 
DNA-based approaches may not be suitable for studies of functional ecology. When the objective of a study is to characterize active fungi, the inert background community is not relevant.

\section{Conservation vs. understanding functionality}

DNA-based approaches generally provide information on the successional stages that the fungal community has passed through, over time, because DNA accumulates within the environmental pool. Although DNA is a phosphorusrich molecule which plants and microbes may compete for in the soil, it has been reported to persist in the top layer $(0-15 \mathrm{~cm})$ for few days up to several years (Nielsen et al. 2004; Pietramellara et al. 2009). Levy-Booth et al. (2007) reviewed that the persistence of recombinant DNA in field soil ranged from 77 days to at least 2 years. This is because DNA can be protected against nuclease degradation by its adsorption on surface-reactive particles in soil, i.e. clay, sand, silt and humic substance (Pietramellara et al. 2009). Thus, both active and inactive fungal taxa can be identified using DNA-based approaches in environmental samples (Anderson and Parkin 2007; Bastias et al. 2007). This can deliver results particularly relevant to conservation or natural resource management research. In an environment where DNA is retained, sampling at a late stage of decomposition can provide much information about the fungal taxa associated with the entire decomposition process. However, the drawback is that it is impossible to assign correct functional roles within successional stages of decay as some fungal taxa may have been actively growing at different successional stages. This situation is more severe in an environment where DNA is not retained. The uneven persistence of DNA from different fungal species and/or substrate quality (i.e. soil types, humic substances, Levy-Booth et al. 2007; Pietramellara et al. 2009) may bias both the existence and relative abundance of each fungal taxon within the community. This is the major obstacle for the understanding of the functional roles of fungi in the decomposition process and of their relationships with environmental factors. According to the definition of an ecological community given by Palmer and White (1994) as "the living organisms present within a space-time unit of any magnitude", dead fungi identified from DNA-based analysis should be therefore excluded from the community.

\section{What is a suitable target for assessing fungal activity?}

Metabolically active cells transcribe more rRNA for ribosome synthesis than inactive cells. In the case of bacteria, it has been proved that rRNA content is highly correlated with metabolic activity and therefore commonly used for quantification of their activity (Wagner 1994). However, this correlation has not yet been validated for fungi and some concerns to the use of rRNA content as a fungal activity marker have been proposed (Rajala et al. 2011). Some specific types of RNA have been used as markers for fungal activity, i.e. $18 \mathrm{~S}$ rRNA, $28 \mathrm{~S}$ rRNA, mRNA of proteincoding genes and the ITS region still contained in precursor RNA (Anderson and Parkin 2007; Bastias et al. 2007; McGrath et al. 2008; Rajala et al. 2011; Baldrian et al. 2012). However, to date, the best possible marker has not been identified. A suitable marker for fungal activity should have short life span but allow direct detection from environmental samples, be specific, easy to detect and provide high resolution for fungal identification (Anderson and Parkin 2007; Rajala et al. 2011). Life spans of mRNA (3 min to more than 90 min; Wang et al. 2002) and precursor RNA containing ITS regions (a few minutes; Kos and Tollervey 2010) are shorter than that of 18 S rRNA (Rajala et al. 2011). Secondary structure and the presence of structural proteins can increase the life span of $18 \mathrm{~S}$ rRNA because of slower degradation, thus the fungal activity indicated by mRNA and precursor rRNA can be considered to be more recent and represent the active community during the last few minutes or hours before sampling (Rajala et al. 2011). Both 18S rRNA and mRNA obtained by direct extraction suffer from PCR amplification bias (Rajala et al. 2011), and restricted nucleotide sequence databases limit the potential for determining taxonomic affiliation (Anderson and Parkin 2007). Precursor RNA containing ITS regions has been proposed as a suitable marker (Rajala et al. 2011). It is amplifiable by RT-PCR directly from environmental samples (Anderson and Parkin 2007; Bastias et al. 2007; Rajala et al. 2011; Baldrian et al. 2012), and it also provides good resolution for fungal taxonomy via BLAST searches at the genera or species level (Anderson and Parkin 2007). However, some cases of intraspecific variation have been reported (Müller et al. 2007) and for fungal taxa, it is too variable to allow reliable multiple sequence alignment and subsequent phylogenetic placement and OTU delimitation. Other than rRNA, some specific types of biochemical markers have been used for quantification of fungal biomass and/or fungal activity, for example certain types of fatty acids in the neutral lipid and phospholipid fatty acid fractions as well as ergosterol content. The reliability of these markers, alone or coupled with stable isotope probing, has been questioned because different fungal species may vary greatly with respect to the amount of these biochemical markers; indeed, various studies have produced conflicting results (Malosso et al. 2004; Högberg 2006). Ergosterol has been shown to persist in the environment after fungal death, and it may be detected from inactive fungi, thus it may 
not reflect the active fungal community (Mille-Lindblom et al. 2004).

\section{Detection of precursor rRNA containing ITS regions in environmental samples}

In fungi, the main rRNA operon comprises $18 \mathrm{~S}$ rRNA gene, ITS1, 5.8S rRNA gene, ITS2 and 25/28 rRNA gene. rDNA is transcribed by RNA polymerase I to generate large single precursor molecules. Although, ITS regions are removed from the main precursor rRNA molecule in post-transcriptional processing, leaving the mature 5.8S rRNA, 18S rRNA and 25/28S rRNA for ribosome formation (Kos and Tollervey 2010), metabolically active fungi are continuously transcribing rRNA precursor molecules and their ITS regions can be detected in the precursor rRNA pool (Anderson and Parkin 2007; Bastias et al. 2007; Rajala et al. 2011; Baldrian et al. 2012). Nevertheless, due to the fast turnover rate of this precursor rRNA, appropriate sampling and processing methods are needed, since any manipulations after sampling can induce transcription of certain species. Fixing of RNA extracts after in situ extraction of the samples with liquid nitrogen is a promising method to deal with this problem. Alternatively, immediate freezing of the samples using liquid nitrogen also can be used (Rajala et al. 2011; Baldrian et al. 2012). Chemical stabilization of nucleic acids such with commercial preservation solutions could be a viable option too. To date, ITS rRNA sequences have been successfully detected in various types of environmental samples, including soil (Anderson and Parkin 2007; Baldrian et al. 2012), litter (Baldrian et al. 2012) and wood (Rajala et al. 2011). RT-PCR is capable of detecting precursor rRNA ITS regions (Anderson and Parkin 2007; Bastias et al. 2007; Rajala et al. 2011; Baldrian et al. 2012). Pure RNA can be reverse transcribed into complementary DNA (cDNA) using Moloney murine leukaemia virus reverse transcriptase and fungal ITS primers (Anderson and Parkin 2007; Rajala et al. 2011) or random hexamer primers (Baldrian et al. 2012). Amplified cDNA can then be used for further analysis of the active fungal community.

\section{Comparisons of fungal communities obtained by rDNA and precursor rRNA containing ITS regions}

It has been reported that, in soil and wood samples, fungal communities characterized on the basis of rDNA and precursor rRNA molecules are clearly different in their structure, composition and richness (Anderson and Parkin 2007; Bastias et al. 2007; Rajala et al. 2011). Baldrian et al. (2012) recently found no differences in fungal diversity using rDNA and precursor rRNA from litter and organic layers of spruce forest, but significant differences in the composition of fungal taxa and, for example, several highly active fungi were of low abundance or even disappeared from the DNA pool. In addition, Rajala et al. (2011) found that the richness of fungal species determined using precursor rRNA analysis increased with decay classes but the same trend was not observed using rDNA analysis. This work also demonstrated the clear functional role of different active fungi in the successional community of decomposing wood based on precursor rRNA analysis, whilst DNA analysis was unable to show this. Rajala et al. (2011) also compared relationships between fungal community structures obtained either by rDNA- or precursor rRNA-based techniques and 13 wood quality factors, 5 among them length, surface area, volume, carbon content and $\mathrm{C} / \mathrm{N}$ ratio, yielding different results. The rDNA-based technique revealed a significant relationship between fungal community structure and these five factors, while the precursor rRNA-based technique indicated that there were no significant relationships. This is the first recorded occurrence of such a discrepancy (Rajala et al. 2011) and poses a number of questions for the ecologist: (1) how do we deal with and interpret the relationships between fungal community structure and substrate or environmental factors derived from rDNA? And (2) do such relationships tell us anything? The results from the comparisons of rDNA- and precursor rRNAbased techniques demonstrate that the background revealed by rDNA analysis is real but can be excluded from the results by using precursor rRNA-based techniques. Once this background is no longer clouding the picture, the active fungi in the community, which do have functional roles in the decomposition process, can be identified (Rajala et al. 2011).

\section{Applications}

Precursor rRNA containing ITS regions can be used in conjunction with fingerprinting and non-fingerprinting techniques to characterize the active fungal community. To date, denaturing gradient gel electrophoresis and terminal restriction fragment length polymorphism are the only fingerprinting techniques which have been combined with the analysis of precursor rRNA molecules, although there is great potential to use precursor rRNA molecules in conjunction with other fingerprinting techniques. Baldrian et al. (2012) successfully isolated the fungal precursor rRNA containing ITS1, 5.8S rRNA and ITS2 from an environmental rRNA pool, and this is the key to success for other fingerprinting techniques, such as automated ribosomal intergenic spacer analysis and single-strand conformation polymorphism, which target this region. Although fingerprinting techniques are commonly used for investigating the differences between microbial communities, it has been suggested that direct comparison of different community fingerprints 
obtained by rDNA and precursor rRNA molecules is inappropriate because of their dissimilar motilities (Rajala et al. 2011). Comparisons using richness and/or diversity indices are more appropriate. For non-fingerprinting techniques, precursor rRNA molecules have been successfully combined with 454 pyrosequencing to characterize the active fungal community (Baldrian et al. 2012). However, there appears to be no published research describing the use of precursor rRNA molecules with cloning techniques to investigate fungal communities.

\section{Conclusions}

Precursor rRNA containing ITS regions is an emerging and interesting molecular marker for determining fungal activity and characterizing the active fungal community in decomposing substrates. Although a small number of studies using this marker have been reported, they do have high impact on molecular fungal ecology, and increase our understanding of the functional roles of fungi in the decomposition process. Further research on the application of precursor rRNA-based techniques to characterize the active fungal community in different ecosystems and/or geographical areas is needed, especially on investigating relationships between the active community structures and enzyme production and/or environmental factors. These relationships are still unclear, and results may differ from those obtained by rDNA-based techniques.

Acknowledgments The writing of this paper was funded in part by contributing projects to DFG Priority Program 1374 on "InfrastructureBiodiversity-Exploratories” (KR 3587/1-1, KR 3587/3-2).

\section{References}

Anderson IC, Cairney JWG (2004) Diversity and ecology of soil fungal communities: increased understanding through the application of molecular techniques. Environ Microbiol 6:769-779

Anderson IC, Parkin PI (2007) Detection of active soil fungi by RTPCR amplification of precursor rRNA molecules. J Microbiol Methods 68:248-253

Baldrian P, Kolarik M, Stursova M, Kopecky J, Valaskova V, Vetrovsky T (2012) Active and total microbial communities in forest soil are largely different and highly stratified during decomposition. ISME J 6:248-258

Bastias BA, Anderson IC, Xu Z, Cairney JWG (2007) RNA- and DNA based profiling of soil fungal communities in a native Australian eucalypt forest and adjacent Pinus elliotti plantation. Soil Biol Biochem 39:3108-3114
Corinaldesi C, Beolchini F, Dell'Anno A (2008) Damage and degradation rates of extracellular DNA in marine sediments: implications for the preservation of gene sequences. Mol Ecol 17:39393951

Gange AC, Gange EG, Sparks TH, Boddy L (2007) Rapid and recent changes in fungal fruiting patterns. Science 316:71

Högberg MN (2006) Discrepancies between ergosterol and the phospholipid fatty acid 18:2(6,9) as biomarkers for fungi in boreal forest soils. Soil Biol Biochem 38:3431-3435

Kos M, Tollervey D (2010) Yeast pre-rRNA processing and modification occur cotranscriptionally. Mol Cell 37:809-820

Kubartová A, Ranger J, Berthelin J, Beguiristain T (2009) Diversity and decomposing ability of saprophytic fungi from temperate forest litter. Microb Ecol 58:98-107

Kulhánková A, Béguiristain T, Moukoumi J, Berthelin J, Ranger J (2006) Spatial and temporal diversity of wood decomposer communities in different forest stands, determined by ITS rDNA targeted TGGE. Ann For Sci 63:547-556

Levy-Booth D, Campbell R, Gulden R, Hart M, Powell J, Klironomos J, Pauls K, Swanton C, Trevors J, Dunfield K (2007) Cycling of extracellular DNA in the soil environment. Soil Biol Biochem 39:2977-2991

Malosso E, English L, Hopkins DW, O'Donnell AG (2004) Use of ${ }^{13} \mathrm{C}$-labelled plant materials and ergosterol, PLFA and NLFA analyses to investigate organic matter decomposition in Antartic soil. Soil Biol Biochem 36:165-175

McGrath KC, Thomas-Hall SK, Cheng CT, Leo L, Alexa A, Schmidt S, Schenk PM (2008) Isolation and analysis of mRNA from environmental microbial communities. J Microbiol Methods $75: 172-176$

Mille-Lindblom C, von Wachenfeldt E, Tranvik LJ (2004) Ergosterol as a measure of living fungal biomass: persistence in environmental samples after fungal death. J Microbiol Methods 59:253-262

Müller MM, Valjakka R, Hantula J (2007) Genetic diversity of Lophodermium piceae in South Finland. Forest Pathol 37:329-337

Nielsen KM, Ray JL, van Elsas JD (2004) Natural transformation in soil: microcosm studies. Molecular microbial ecology manual, 2nd edn. Kluwer, Dordrecht, pp 1-12

Palmer MW, White PS (1994) On the existence of ecological communities. J Veg Sci 5:279-282

Pietramellara G, Ascher J, Borgogni F, Ceccherini MT, Guerri G, Nannipieri P (2009) Extracellular DNA in soil and sediment: fate and ecological relevance. Biol Fertil Soils 45:219-235

Purahong W, Hyde KD (2011) Effects of fungal endophytes on grass and non-grass litter decomposition rates. Fungal Divers 47:1-7

Rajala T, Peltoniemi M, Hantula J, Mäkipää R, Pennanen T (2011) RNA reveals a succession of active fungi during the decay of Norway spruce logs. Fungal Ecol 4:437-448

Stenlid J, Gustafsson M (2001) Are rare wood decay fungi threatened by inability to spread? Ecol Bull 49:85-91

Trap J, Bureau F, Akpa-Vinceslas M, Decaens T, Aubert M (2011) Changes in humus forms and soil $\mathrm{N}$ pathways along a 130-year-old pure beech forest chronosequence. Ann For Sci 68:595-606

Wagner R (1994) The regulation of ribosomal RNA synthesis and bacterial cell growth. Arch Microbiol 161:100-109

Wang Y, Liu CL, Storey JD, Tibshirani RJ, Herschlag D, Brown PO (2002) Precision and functional specificity in mRNA decay. Proc Natl Acad Sci U S A 99:5860-5865 